\title{
Situative Interdisciplinarity: Empirical Reflections on Ten Years of Cross-Disciplinary Research
}

\author{
Rachel Reckinger \\ Christian Wille
}

University of Luxembourg

Doi: 10.2478/ajis-2018-0055

\begin{abstract}
Given the current call for interdisciplinarity, we reflect on pragmatic methodological implementations of collaborative research - by drawing on empirical evidence from two large-scale cross-disciplinary research projects and by theoretically framing them in trilingual contexts (German, French, and English). These are two major innovations compared to the existing body of literature in this domain. Our empirical analysis shows that multi-, inter- or trans-disciplinary collaboration is an oscillating process along a spectrum of cross-disciplinarity - spanning additive, converging and synthesizing work patterns, i.e. multi-, inter-, and transdisciplinarity. Such an umbrella-term avoids the common amalgamation of 'interdisciplinarity' as the overarching category (cross-disciplinarity of whatever form) and one of the relevant subcategories (the specific work form that a research team chooses). Concretely, if the majority of methods are developed through communal negotiation processes, then a truly interdisciplinary analysis of research results can only be guaranteed through recursive self-reflexive loops. Initial research questions may still be additive and interactions can oscillate during the project process between addition und tentative convergence. We label this process situative interdisciplinarity. Multi-, inter- and transdisciplinarity are thus subsumed as a processual entity: flexible, possibly hybrid subforms of cross-disciplinarity. It needs constant reactivation, framing, timing and mediation by project managers. The major challenge lies in the collaborative transfer of concepts, theories, methods and research subjects. This transfer requires translation, explication and transposition of the various disciplinary 'languages' and can only be converged in an open-minded, team-oriented and reflexive work environment.
\end{abstract}

Highlights: *Cross-disciplinarity is a continuum comprising multi-, inter-, transdisciplinarity, i.e. addition, convergence, synthesis. *Co-existence and oscillation between multi-, inter- and transdisciplinarity during a project is the norm, not the exception. *Skilled, sensitive coordinators as well as research projects' recursive structure ensure ongoing monitoring of this process. *A collaborative transfer of concepts, theories, methods, research subjects requires translation, explication, transposition. ${ }^{*} T h i s$ major challenge can only be converged in an open-minded, team-oriented and reflexive work environment

Keywords: Cross-Disciplinarity, Empirical Self-Evaluation, Pragmatic Methodological Implementation, Multidisciplinarity, Interdisciplinarity, Transdisciplinarity

\section{Introduction}

This paper proposes an empirical analysis of cross-disciplinary cooperation as a form of 'situative interdisciplinarity' on a continuous spectrum, as an alternative to more static interdisciplinary 
models. While disciplinary research is (and probably will remain) strong, there is a parallel trend towards 'interdisciplinarity' - often used as a catchphrase. Hands-on cross-disciplinary cooperation presents its own challenges, which we will address with the concept of 'situative interdisciplinarity'.

Based on empirical evidence from ten years' experience with two large-scale crossdisciplinary research projects, we will reflect on the methodological yet pragmatic implementation of collaborative research. We hope to contribute to the growing body of literature on cross-disciplinary scientific cooperation from a sociology of science perspective in trilingual bodies of literature (German, French and English). In philosophical or sociological reflections on science, interdisciplinarity and transdisciplinarity are the forms of collaboration that are most often analysed; we would like to include multidisciplinarity as a facet of cross-disciplinarity that we see as a continuous spectrum.

We start by defining concepts for possible cross-disciplinary collaboration, followed by an outline of the two research projects and the methodology to gather the data for the empirical selfevaluation on which this paper is based. We then provide observations on the main quandaries of cross-disciplinary collaboration, tying together theoretical insights and methodological recommendations with our empirical analysis. As an outcome, we suggest the notion of 'situative interdisciplinarity', meaning that different types of cross-disciplinarity can coexist during different project stages, enabling future research teams to have realistic expectations of their progressive performance.

\section{Cross-Disciplinary Collaboration: Definitions and Concepts}

Most authors agree on the fuzzy character of the concept of cross-disciplinary collaboration (e.g. Jungert, 2010; Frodeman, Thompson Klein \& Mitcham, 2010; Frodeman, Thompson Klein \& Pacheco, 2017; Thompson Klein, 1990). They produce consensual definitions of its relevant forms, which are generally reflected critically, to the point that "scepticism towards the term of interdisciplinarity has already congealed to a cliché" (Gehring, 2013, p. 134). Another constant is the reference to disciplinarity as an institutional starting point. Different types of cross-disciplinarity as well as the participating disciplines have been central in our experience.

\subsection{Continuum of Different Forms of Cross-Disciplinary Collaboration}

We choose the term cross-disciplinary collaboration (Wille, Reckinger, Kmec \& Hesse, 2016) with reference to Balsiger's "cross-disciplinary scientific practice" $(2005$, p. 142$)$ to encompass the main types of scientific collaboration, ranging from multidisciplinarity to interdisciplinarity and transdisciplinarity ${ }^{1}$ (Crowley, Gonnerman \& O'Rourke, 2016). Using an umbrella term favours a perception of collaborative research with the flexible imbrications of its relevant subforms, seen as interrelated, interacting among each other and situated on a continuum. Like most authors, we see a progression from multidisciplinarity to interdisciplinarity and transdisciplinarity, but we do not consider those forms of collaboration as linear or teleological steps.

Multidisciplinarity (and pluridisciplinarity): This refers to the coexistence of disciplines in one subject area. The disciplines work on specific sub-aspects of the common area of investigation within 'their' subject matter. There are not necessarily common research questions, nor a common methodology to converge the different viewpoints and in fine not much transfer of knowledge (Weber, 2010b, p. 100). The juxtaposed disciplines share pertinent information and there is potential to broaden the perspective on the common field of investigation (Jungert, 2010, p. 2). Such collaboration typically fosters an acceptance of the inherent plurality of societal facts, as researchers "regard different aspects in turn but not simultaneously" (Buanes \& Jentoft, 2009, p. 450). The term multidisciplinarity is often used synonymously with pluridisciplinarity, but some

${ }^{1}$ O'Rourke (2017, p. 276) also mentions "cross-disciplinary research", but only uses it as a shortcut for interdisciplinary and transdisciplinary research, not as an overarching category intended to avoid amalgamation, as we do. 
authors see the latter as the first step of more intense relations between disciplines via a loose exchange of findings and problems in a common subject area (i.e. Jungert, 2010; Maihofer, 2005). In this type of collaboration, diverse perspectives are merely added to one another. They may be "mutual and cumulative but not interactive" (Thompson Klein, 1990, p. 56; see Frodeman et al., 2017, p. 17) nor integrative (see Wille, Reckinger et al., 2016, p. 55ff.).

Interdisciplinarity: This term is most frequently used in the context of cross-disciplinary collaboration. It designates a collaborative or sequential "work form" (Weber, 2010b, p. 99) with a "will to effect a transfer" (Gehring, 2013, p. 137) - a temporary collaboration of scientists from different disciplinary backgrounds. This form of knowledge production relies on disciplines as a point of departure and reconnection: the disciplines remain 'untouched', but enter into a reciprocal dialogue of convergence and combination during which they are able to "collaborate in a multiperspective manner [...]" (Maihofer, 2005, p. 198). This constellation is designed to take the optimum out of the different disciplines for shared research questions (idem, p. 199).

Interdisciplinary collaboration requires an understanding that among the perspectives projected simultaneously on the same collectively defined phenomenon, none is superior. Instead, "shifting perspectives" (see Buanes \& Jentoft, 2009, p. 450f.) is the main effort, in order to develop original perspectives, either as a synthesis of existing ones or genuinely novel ones ${ }^{2}$. This collective broadening of the vision on complex societal issues is the main argument to invoke interdisciplinary collaborations instead of mere disciplinary ones. Yet interdisciplinarity constructs its subject of study and reduces complexity in much the same way disciplines do.

To summarise, "all interdisciplinary activities are rooted in the ideas of unity and synthesis, evoking a common epistemology of convergence" (Thompson Klein, 1990, p. 11). It is to some extent a subjective appreciation, as it is likely that "anyone regarding science as something that is divided into neatly definable boxes [...] will perceive more need for transdisciplinary collaboration than someone wo sees the organization of science more like something determined by questions, (families of) problems, themes and subject matters" (Löffler, 2010, p. 160).

Some authors propose internal differentiations of interdisciplinarities, either regarding their quality or their mode of functioning (see Frodeman et al., 2017, p. 18-24). For instance, Löffler (2010, p. $164 \mathrm{ff}$.) and Heckhausen (quoted in Jungert, 2010, p. 4ff.) propose a gradation ranging from "niceto-know interdisciplinarity" to "unifying interdisciplinarity" with various intermediary stages (see Wille, Reckinger et al. 2016, p. 56ff.), depending on the depth and reciprocity of the interactions between disciplines. On the other hand, Mittelstraß (quoted in Sukopp, 2010, p. 21) suggests internal distinctions that are based on the common ground produced by the interdisciplinary process: theoretical interdisciplinarity (using paradigms that span disciplines and theories), practical interdisciplinarity (research structures that deal with questions around "phenomena of a specific scale with all their facets, and not around disciplinary subjects" (idem, p. 22)) and methodological interdisciplinarity (designating a "methodological continuity or congruence" (idem, p. 22) of similar methods in the planning, execution or evaluation of scientific research projects) ${ }^{4}$.

\footnotetext{
${ }^{2}$ Having said that, see Mäki, Walsh \& Fernandez Pinto (2018, p. 3) for a discussion on "scientific imperialism", where interdisciplinary set-ups take into account asymmetric contributions from various disciplines.

${ }^{3}$ In recent decades, this convergence or integration has tended to shift "from the pre-given to the emergent, and from universality to hybridity and contextuality" (Thompson Klein, 2015, p. 11).

${ }^{4}$ Mittelstraß (2005, p. 21ff.) links these adjectives to transdiciplinarity. Mittelstraß argues that "interdisciplinarity in the correctly understood sense does not move to and fro between fields or disciplines or hover, almost like the absolute spirit, above fields and disciplines. On the contrary, it cancels out constrictions inherent to a field or discipline where these obstruct the elaboration of problems and appropriate research activities; it is, in actual fact, transdisciplinarity" (idem, p. 19). For this reason, Sukopp applies these adjectives analogously to interdisciplinarity. Given our empirical experience with the implementation of different types of cross-disciplinary collaboration - the practice of which has been complex, simultaneously demanding and rewarding, in either case requiring a high level of reflexivity - we opt, like most authors, for a clear distinction between interdisciplinarity and transdisciplinarity. Even though the idealistic notion of an in-depth interdisciplinarity which merges into transdisciplinarity is appealing, the practice of such processes seems less like smooth superpositions than rigorous, long-term negotiations.
} 
Our collaborative approach pertains to this cursory synopsis of the conceptual understanding of interdisciplinarity. As an institutionally funded large-scale research project around the paradigms of identity, space and borders, we practised theoretical and practical interdisciplinarity; with our quantitative and qualitative methods of empirical and textual data analysis, we additionally practised methodological interdisciplinarity. In terms of the type of interactions, our research practice started with polite informative exchanges and continues with more committed determination of goals, meanings and strategies.

Transdisciplinarity (and postdisciplinarity): Transdisciplinarity tends to transcend disciplines and academia when different experts collaborate. While interdisciplinarity mixes disciplines and produces a "dialectical synthesis" (Thompson Klein, 1990, p. 66) in a given timeframe, transdisciplinarity implies a long-term fusion of disciplines (see Lawrence, 2010, p. 129; Després \& Lawrence, 2004; Stokols, 2006; Thompson Klein, 2015). Its ultimate contribution resides in "transcending, regrouping and reconfiguring of questions, theories and methods" without linking them back to individual disciplines (Maihofer, 2005, p. 200), with the aim to grasp the "interconnectedness of all aspects of reality" (Thompson Klein, 1990, p. 66) in a "unified rationality" (Weber, 2010b, p. 100).

At the same time, transdisciplinarity denotes a form of collaboration where specific issues are addressed in an integrative and application-orientated way (see Defila et al., 2006, p. 34). Here, the concept of postdisciplinarity dissociates itself from the dichotomy of academic knowledge production on the one hand and non-academic knowledge production on the other. It is concerned - similar to the transdisciplinary approach - with an inductive-reflective process in which the questions to be examined, the methods used and the theories and solutions developed are generated in the process (see Maihofer, 2005, p. 201).

From the typology of multi-, pluri-, inter-, trans- and postdisciplinarity presented above - as a series of increased complexity with diminishing disciplinarity - we derive three basic models of cross-disciplinary collaboration (see Wille, Reckinger et al., 2016, p. 58ff.), according to their processes of collaboration ${ }^{6}$.

1) Cross-disciplinary collaboration as addition should be understood as a collection of disciplines that work on a common (research) subject and merely share information. In this scientific practice, which would belong to multi- and/or pluridisciplinarity, there is no substantial exchange and no crossing of disciplinary borders.

2) Cross-disciplinary collaboration as convergence can be found where there is an exchange in the form of integration, confluence, combination and imbrication between disciplines grouped around a common research topic, leading to the development of original perspectives, but without the participating disciplines 'dissolving'. This form of collaboration potentially brings about 'disorders' of the familiar research practice and requires researchers to display certain social skills (e.g. tolerance for ambiguity or empathy) in order to exploit them productively (see Wiesmann et al., 2008, p. 437ff.).

3) Cross-disciplinary collaboration as synthesis suggests scientific practices that overcome disciplinary and institutional systems in a problem- and/or solution-orientated way. Typically, in trans-/postdisciplinarity, the research topics as well as the conceptual and methodological tools are not predefined but are developed in a deductive-recursive procedure that mostly also involves non-academics (see ibid., p. 437f.).

Thompson Klein (2017, p. 16) has proposed a similar graduation, but doesn't stress the characteristic points of addition, convergence and synthesis. She also does not introduce the

\footnotetext{
${ }^{5}$ One of the institutional goals of these two research projects was to foster the dialogue and integrative collaboration among the different disciplinary institutes of the Research Unit IPSE, optimising interdisciplinary practices among social sciences and humanities. Therefore, transdisciplinarity was not an aim and no extraacademic collaborations were set up in the context of IDENT and IDENT2.

${ }^{6}$ Huutoniemi \& Rafols (2017, p. 499) proposed a similar model in three parts, but theirs is based on the type of knowledge production - "breadth, integration and transformation" - which they link respectively to multidisciplinarity, interdisciplinarity and transdisciplinarity.
} 
concept of a continuous spectrum ${ }^{7}$ or an umbrella term to express that the different types of crossdisciplinary collaboration are mere stages on a continuum. Instead, she refers to "typologies of interdisciplinarity" out of which interdisciplinarity is one, alongside multidisciplinarity and transdisciplinarity. In her visualisation, "interdisciplinarity" is both the general title and a subcategory. We show that an understanding of the empirical, hybrid oscillations between the three main forms (multidisciplinarity, interdisciplinarity and transdisciplinarity) can best be achieved if one conceptualises their relationships as a fluid spectrum from addition via convergence to synthesis. $A$ distinct name for this spectrum - cross-disciplinary collaboration - is more accurate and avoids this common amalgamation.

An essential point to this typology is that hybrid forms are the rule and not the exception in scientific practice, as Mittelstraß (2005, p. 20) showed. Our empirical self-evaluation confirms this, leading us to develop the notion of situative interdisciplinarity as a key feature of cross-disciplinary collaboration. We developed the following model/diagram to symbolise the double-sided movement of cross-disciplinary forms of collaboration, aiming either (successively or in turn) at the addition, convergence or synthesis of disciplines. This continuous oscillation varies according to the individual researchers and the project stages ${ }^{8}$.

\section{Continuum of Cross-Disciplinary Collaboration}

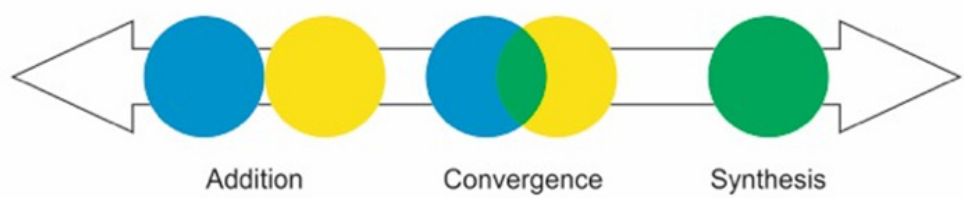

Figure 1: Continuum of cross-disciplinary collaboration with its three basic subforms (concept: Christian Wille and Rachel Reckinger; design: Malte Helfer).

\subsection{Disciplinarity and Interdisciplination}

Given the emphasis theorists place on disciplines as constitutive elements of cross-disciplinary collaboration - particularly in the case of interdisciplinarity - we would like to expand on some points that are of concern to our approach.

"Disciplines are best described vaguely as bundles of terms, central research questions, methods, theories and institutionalizations. As units that have evolved in the history of science they are negotiable within their limits and also in their essence" (Wahrig \& Zuber, 2010, p. 218). They each have a stock of knowledge and specific views on the "correct procedure for structuring reality" (Sukopp, 2010, p. 21). To do that, they are characterised by an inherent double-sidedness: they are "structures that educate, facilitate, but they are also disciplining, regulating structures" (Hark, 2005, p. 76f.), defining what is conventionally accepted as worth knowing (idem, p. 77), even though they

\footnotetext{
${ }^{7}$ Hall, Stipelman, Vogel \& Stokols (2017, p. 341) name a "continuum of disciplinary integration", ranging from "within disciplines" to "across disciplines": unidisciplinary, multidisciplinary, interdisciplinary, transdisciplinary. They also mention an overarching category of cross-disciplinarity, but don't argue the epistemological or methodological reasons for doing so. Because of this lack of theorisation in their schema, cross-disciplinarity doesn't appear as the umbrella continuum that we suggest it should be viewed as in order to avoid amalgamation.

${ }^{8}$ See Section 4.4 (Appraisal of Individual Cross-Disciplinary Research Practice) and Section 5 (Discussion: Situative Interdisciplinarity).
} 
have always been somewhat porous among each other (Jacobs, 2017, p. 36).

By being a memory-regulating mechanism, providing a particular "thought world" (Douglas, 1986 , p. 14), disciplines can be viewed as institutions, as "regulatory systems with formal and informal rules and sanctions, cognitive systems that control and develop their own respective knowledge base, and as cultural systems with particular norms and values with regard to how issues should be studied" (Buanes \& Jentoft, 2009, p. 448). Despite fundamental "differences between the social and nature science disciplines, they are strikingly similar as institutions" (ibid.). This point stresses the applicability of the raised issues to all types of collaborating disciplines in cross-disciplinary endeavours.

The cross-referencing between disciplinary and interdisciplinary research can be defined as an "interplay between epistemic institutions" (Castán Broto et al., 2009, p. 924). The notion of interplay refers to institutional interactions at different scales ${ }^{9}$. At each of these levels, disciplinary institutions "shape the practice of interdisciplinary research, whether hindering or facilitating it" (ibid., p. 925). A substantial aspect in this context is the fact that scientific reputations, peer reviews, recognition, rankings and career establishment are still largely disciplinary (see Wahrig \& Zuber, 2010, p. 232). By producing further ramifications in knowledge production, cross-disciplinary collaboration can, paradoxically, also be an intermediary state for new forms of disciplinarity (see Hacking, 2010, p. 194; Defila et al., 2006, p. 33; Jacobs, 2017, p. 37f.). Paradoxically, the confrontation with other participating disciplines during cross-disciplinary collaboration triggers a high(er) degree of individual disciplines' self-reflexivity about their own conditions and manners of working, thinking and proceding - disciplines are not only relativised, but also refreshed and even partly renewed. Similarly, only selfreflexive disciplines can produce critical interdisciplinarity (see Hark, 2005, p. 85).

The term "interdisciplination", conceptualised by Weber as a "restructuring of knowledge, the development of a new episteme - not primarily along disciplinary lines, but possibly along particular theoretic frameworks", entailing specific and self-reflexive translation and transposition tasks (see 2010 b, p. 106) encapsulates all the abovementioned aspects. Firstly, there are the intertwined and flexible dialectics of disciplinary and interdisciplinary relationships. Secondly, there is the understanding of a working method that can be open-creative or restrictive-formal, in the sense that "disciplines discipline disciples" (Barry, Born \& Weszkalnys, 2008, p. 20) in more or less enabling ways. Thirdly, there's the idea of an ongoing and flexible process of negotiation towards a creative cross-disciplinary scientific culture. In the first understanding of interdisciplination ${ }^{10}$, the focus lies on 'inter-', while in the second one it rests on '-disciplination' and in the third one on '-ation'.

In our research projects, the ideal of cross-disciplinary research is not to become "disconnected from one's original discipline(s) but rather to push the boundaries of a discipline, including questioning its main tenets" (Castán Broto et al., 2009, p. 928). This process is "much messier and more iterative" (Calhoun, 2017, p. 125) than generally acknowledged, as our empirical analysis goes to show.

\section{Empirical Framework and Methodology}

\subsection{The Two Research Projects we are Drawing on}

Between 2007 and 2010, the interdisciplinary research project IDENT - Socio-cultural identities and identity policies in Luxembourg brought together the institutes represented in the research unit IPSE (Identités, Politiques, Sociétés, Espaces) at the University of Luxembourg. The team comprised 28 researchers, including the project manager and two coordinators.

\footnotetext{
${ }^{9}$ With cross-disciplinary collaboration, these are mainly the organisational level (i.e. universities, funding bodies), the research community level (i.e. colleagues, project team members) and the level of individual research practices (ibid.: 930).

${ }^{10}$ Similarly, but at another level of analysis, Thompson Klein \& Frodeman speak of "interdisciplining humanities" (2017, p. 144) with the aim to evolve the US-based National Endowment for Humanities (NEH)'s current definition of humanities that is, in their view, merely multidisciplinary.
} 
Given the importance of individual and collective identity patterns in modern societies, various forms of identity constructions were identified and investigated in interdisciplinary collaboration. The focus of our dynamic understanding of identities was directed at attribution and appropriation processes of identity options and choices in Luxembourg: the dialectics of what institutions and the media consider as 'desirable' and what is socially 'lived' was investigated in the four thematic areas of spaces, languages, images of self and other as well as everyday cultures. We used quantitative, qualitative and textual-analytical methods. The backdrop was the analysis of socio-cultural milieus in which these contexts articulate themselves.

The results were published in a common volume available in German, French and English: Doing identity in Luxembourg. Subjective appropriations - Institutional attributions - Socio-cultural milieus (IPSE, 2011).

The second research project, IDENT2 - Strategies of regionalisation: Constructing identity across borders, brought together nearly all the institutes represented in the IPSE research unit between 2011 and 2016. The project team included 34 researchers who gathered around the subject of identity constructions in border areas: the findings of the previous IDENT project are expanded in IDENT2 with issues of spatial construction. The 19 empirical case studies inform about historical and current processes of identities and spatial formations of social life. Three key areas were addressed: a power-critical perspective on spaces and identities that focuses on policies and normalisations; a media-orientated perspective on spaces and identities that sees media as constructors and projection surfaces; and a subject-centered perspective that investigates the production of space and identity constructions in the course of everyday cultural practices.

The project work was done by the participating scholars in thematic and accompanying work groups. The thematic work groups each concerned themselves with one of the three research areas, tailoring them to the project's cross-disciplinary research concept in terms of theoretical and empirical principles. This content-related project work was flanked by three accompanying work groups that concentrated on theoretical issues, methodological aspects and the collaboration of the participating disciplines. Their work was important for the overarching research concept and the collaboration between the participating scholars which were moderated, brought together and structured by the project coordinators.

Spaces and identities in border regions. Politics - Media - Subjects (Wille, Reckinger, Kmec \& Hesse, 2016) is the volume of findings published in German and English.

Regarding project design, the main difference between IDENT and IDENT2 is the status of the non-thematic work groups. In IDENT, the focus was on the structural interaction of the four contentrelated work groups plus a transversal one on social milieus. In IDENT2, the thematic work groups were reduced to three, but they were assisted by three more formally established accompanying work groups: 'theory', 'interdisciplinarity' and 'methods' (quantitative as well as qualitative). These were set up recursively, aiming to provide the ongoing research carried out in the thematic work groups with a simultaneous, meta-reflexive frame. Both projects were coordinated by the same tandem of researchers who additionally carried out a case study each in both projects, combining a managerial and researcher function.

IDENT was conceived shortly after the IPSE research unit was established. As its members were involved in an intensive process of negotiating a common research profile that would contribute to a collective sense of institutional, recognisable identity, there was a high motivation for such a collective, overarching endeavour, fostering communality and exchange ${ }^{11}$.

\subsection{Methodology of the Two Empirical Self-Evaluations}

This article synthesises the results of both IDENT and IDENT2 self-evaluations in a comparative

\footnotetext{
${ }^{11}$ The head of IPSE was also the principal investigator of IDENT and eleven professors and senior lecturers participated in the first project. IDENT2 took place in a more firmly established institutional context with more parallel, ongoing research projects (on a smaller scale); at this point, fewer professors and senior lecturers but more postdocs and PhD candidates were involved.
} 
way, situated on a ten-year span of learning experience ${ }^{12}$. It discusses aspects of general interest, transcending the immediate research context in order to provide a reflection on the conditions and project stages and to assess which type of cross-disciplinary collaboration is fruitful at which stage.

We draw on the following questions from the combined quantitative and qualitative questionnaires ${ }^{13}$ :

- Evaluation of the project

- Assessment of the work session formats

- Evaluation of the role of the project coordinators

- Evaluation of the interdisciplinary collaboration

- Assessment of one's own style of working and the work steps in specific work groups.

At the end of each research project, participants ${ }^{14}$ were given a questionnaire the project coordinators developed ${ }^{15}$. These comprised several items for each question that were to be ticked quantitatively on a 4-point scale. The data was evaluated via descriptive statistics (Bortz \& Schuster, 2016). Due to the low number of participants, the representation of frequencies was emphasised; the quantitative results therefore do not have the usual statistical representative, large-scale function, but are useful to point to proportions and tendencies. Both questionnaires were answered reliably, with only minimal fluctuations in the number of answers per question ${ }^{16}$.

Every question was complemented with an invitation to make qualitative, openly formulated comments referring to the quantitatively enumerated criteria per question ("What did you like in particular?") as well as suggesting an open continuation ("What should have been organised differently?"). The qualitative statements were submitted to a "synoptic qualitative content analysis" (Mayring, 2007). The aim was to condense the material to the essential findings without limiting the content.

\subsection{Contextual Analysis of the Two Research Projects}

In our interdisciplination process, the methodological implementation of cross-disciplinarity varied according to the project stage. Publications on methodological implementations in empirical contexts refer almost exclusively to transdisciplinarity (Calhoun, 2017; Pohl et al., 2017; BlättelMink, Kastenholz, Schneider \& Spurk, 2003; Castán Broto et al., 2009; Maasen, Lengwiler, \& Guggenheim, 2006; Pohl \& Hirsch-Hadorn, 2008), but some aspects are also relevant to multi- or interdisciplinarity.

\subsubsection{Overall evaluation}

In the first project, the researchers mainly appreciated the collaboration of involved disciplines and the number of participants, while in the second one this appreciation refers to the overarching conceptualisation, followed by the number of participants, the cooperation of the disciplines as well as the temporal rhythm of the project work. The aspect of exchange was stressed positively in both

\footnotetext{
${ }^{12}$ Besides the identical team of coordinators (who are the main and assistant author of this article), roughly one third of the IDENT2 scholars already participated in the preceding IDENT project, ensuring continuity and communication of collaborative experience.

${ }_{13}^{13}$ For comparability, the questionnaires were near-identical for both self-evaluations.

${ }^{14}$ The number of participants comprised 19 people with IDENT and 26 with IDENT2 - team members plus the director of the project, but minus the project coordinators who were barred for reasons of neutrality, since their performance was also evaluated in the questionnaires.

${ }^{15}$ The questionnaires were operationalised with the online questionnaire software Unipark (www.unipark.com).

${ }^{16}$ The diversification of the items by mean value (average of the ticked evaluations) and modal value (the most frequently ticked evaluation) according to a predefined numeric key aimed to provide additional clarity. More detailed quantitative information can be found in the two IDENT2 working papers on the first and second selfevaluation: http://wwwen.uni.lu/research/flshase/home/publications. This article draws primarily on the qualitative statements and/or synthesis beween both kinds of data gathering from the working papers $N^{\circ} 0$ and $N^{\circ} 7$, published on the cited website.
} 
projects, with the nuance that in the first one the focus was on getting to know each other, while in the second one it was more on insight into other academic cultures.

Both projects were perceived as efficiently organised and favourably evaluated concerning collegial collaboration. Their scientific interdisciplinary 'result' was regarded as the most uncertain feature, even though a critical view on the converged research results was more prominent in the first project. In the second project, the most negative point was an exchange that was perceived as relatively weak between accompanying and content-related work groups, in particular with the work group 'theory ${ }^{17}$. An openness that recognises pluralities, combined with a reflective self-critical attitude points to the awareness of the participants to be able to progressively optimise their collaboration. Concerning the contributions of the individual case studies, participants recommended an early call for written text modules that would form the (modifiable) foundation of further discussions. Such modules would represent documented stages of the road towards a higher interdisciplinary convergence.

In the self-evaluation of the first project, it was questioned whether the cross-disciplinary approach makes sense in principle, whereby two understandings of interdisciplinarity became visible: a negative-defeatist one that focuses on difficulties and a positive-pragmatic one that focuses on process changes. In the second project, this fundamental questioning was absent and only the efficiency of individual work groups was criticised, showing general progress towards more precision in self-assessment.

\subsubsection{Research project coordination}

It is generally acknowledged that cross-disciplinary collaboration, particularly the consent-forming and integration stages, must be managed by project coordinators (Defila \& Di Giulio, 2017, p. 335; Defila et al., 2006, p. 38). The coordinators' main task is providing "clearly structured and timed means of communication, integration and reflexivity" (Wiesmann et al., 2008, p. 438).

They should be competent in organising "consensus" forming (Defila \& Di Giulio, 2017, p. 332). They must also have perceptive insight into the potential sensitivities of participating disciplines $^{18}$ (Defila et al., 2006, p. 44). Integration of perspectives and knowledge of different disciplines (in the case of multi- and interdisciplinarity) and actors (in the case of transdisciplinarity) have to take into account the recursive character of cross-disciplinary collaboration.

If the synthesis is carried out only at the end of research processes, the superficiality of connections can hardly be avoided. This has to be handled pragmatically, as shown in our projects by the differently paced advancements of the case studies, despite the project coordinators' efforts to structurally and dialectically implement, negotiate and reinforce those integration methods.

In both projects, the coordinating activities of centralising work flow and mediating between disciplines and individuals were highly appreciated. In particular, documentation of work processes and coordination across the project (especially the time schedule) as well as content-related prestructurings and moderation of meetings were seen as helpful. It was critically remarked that there should be more variation in the coordinating team concerning disciplines in order to have a broader foundation in the interdisciplination process. A further desideratum was that the coordinators should have the possibility to demand binding written deliverables.

\subsubsection{Researchers' expectations}

The expectations of the participants were largely met in both projects: for IDENT, $79 \%$ of the team

\footnotetext{
17 Hall et al. (2017, p. 339) argue that "teams that are highly cross-disciplinary will benefit from processes that externalize group cognition, so they can ensure that members share a common understanding of the research problem and clarify the contribution of each participating discipline." Therefore, our critical self-assessment may be a typical feature inherent to such a process rather than a perceived shortcoming of its progress.

${ }^{18}$ This can also be framed as a learning process yielding an interesting outcome in terms of interpersonal skills for project coordinators.
} 
members ${ }^{19}$ stated that their expectations of the project were fulfilled; for IDENT2, it was $82 \%$. The first project initiated a fruitful communal process that represented added value, particularly in crossdisciplinary team-building, but which is assessed as needing to be further refined, particularly in interdisciplinary scientific production and reflexivity. In the second project, participants' evaluations concerned realistic expectations towards the relation between one's own involvement in a process that is to be shaped communally and the possibly smaller amount of publications. The required openness is characterised as both inspiring and work-intensive.

\section{In-Depth Empirical Analysis of the Main Cross-Disciplinary Quandaries}

\subsection{Main Challenges of Cross-Disciplinary Collaboration ${ }^{20}$}

\subsubsection{Different research cultures and discipline-specific terminology require transpositions and explanations}

The quantitative data in both projects shows that different research cultures and discipline-specific terminology are rated as the most complex challenges in cross-disciplinary interactions (see Eigenbrode et al., 2007, p. 57, for a discussion on "linguistic and conceptual divides"). In the second project, these two items are still seen as the main cross-disciplinary challenges, but less $\mathrm{so}^{21}$. This indicates a clear progression in our cross-disciplinary experience and points to a central characteristic of cross-disciplinary collaboration: the cornerstone constituted by different research cultures and discipline-specific vocabulary will remain at the heart of scientific negotiation processes of cross-disciplinary research teams during all project stages, be they empirical, conceptual, theoretical or methodological. Experienced research teams will gradually acquire the expertise to handle them better. Its persistence is not a dissensual hurdle, but a guarantee of the recursive reflexivity that is needed for this type of collaboration.

Similarly, discipline-specific terminology and different academic cultures (with more or less experience with teamwork and mutual criticism) as well as unequally practised multilingualism were seen as problematic issues in the first project, also qualitatively.

"The project has highlighted how difficult concrete collaboration is, not as a team (that sometimes seems more difficult within the disciplines) but attaining a level that goes beyond polite interaction [...] Here, the different discipline-specific vocabulary constitutes a bigger obstacle than multilingualism because it leads to misunderstandings that can only be solved via metacommunication. I believe one can master this challenge if one takes it seriously ${ }^{\prime 22}$.

Taking this required metacommunication seriously means putting into practice - in a recursive way that is structurally embedded in the project architecture and activated by the project coordination ${ }^{23}$ - four central understandings: the approach of each team member, the methodological tools in each discipline, the discussions each discipline has about the subject as well as the professional costs/benefits of doing cross-disciplinary research for team members (Castán Broto et al., 2009, p. 930).

\footnotetext{
${ }^{19}$ We would like to emphasise again that all percentages in this article are related to very few numbers of respondents. The percentages therefore do not pretend to provide a robust statistical generalisation but show proportions and tendencies among our two samples.

20 This section is based on quantitative and qualitative data from both projects. The qualitative empirical developments are the ones that give insight into the more elusive yet deeper negotiations in the crossdisciplinary interaction process, where sensitivities, hesitations, unspoken hegemonial contests and/or nonverbalised stakes resonate implicitely.

${ }^{21}$ The percentages have decreased to $68 \%$ and $64 \%$ respectively.

${ }_{22}$ Quotes that are not followed by a literature reference stem from our qualitative data.

${ }^{23}$ The importance of this communication issue occurred to us during the first project; in the second one, we implemented it even more consistently by anchoring it in the project structure and making it explicit in the interactions.
} 
In the second project, there were even more extended discussions about this. Almost all statements mention the necessity to explain concepts, translate them and clarify them in the context of discipline-specific vocabulary. The topicality of these aspects remains, but the more experienced approach changes: instead of just naming the differences, the way they are dealt with proceeds pragmatically in a more process- and solution-orientated way. The statements understand discipline-specific vocabulary primarily in the sense of academic cultures, but the purely linguistic aspect also stood out ${ }^{24}$.

The conceptual (and in our case, also linguistic) translation, transposition and explanation of discipline-specific terminology is acknowledged in the literature as the biggest challenge of crossdisciplinary collaboration (Buanes \& Jentoft, 2009, p. 452) ${ }^{25}$. Blättel-Mink et al. (2003, p. 32f.) identify differing disciplinary divides on terminology and perspectives as the main inhibiting factors in cross-disciplinary collaboration, together with the corresponding time investment for translation, meaning the necessity of explicit communication. What they do not highlight is that this translation and transposition effort is an ongoing and long-term process, as our ten-year empirical experience - which is still incomplete in this respect - shows. The transfer of the different disciplines' concepts and methods is of key importance. It should be conducted systematically, accompanied by a rigorous reflexivity on the challenges of these translation and transmittance processes that must not become self-evident (see Löffler, 2010, p. 166).

\subsubsection{Risks of implicit hierarchies between disciplines}

Even though the implicit hierarchisation between disciplines was regarded as the smallest obstacle in quantitative terms, the use of explicitly social-scientific concepts and methods in our two projects was thematised as both inspiring and limiting in the qualitative comments.

These preoccupations refer to the negative extreme of an "unfriendly takeover" by a guiding discipline (Löffler, 2010, p. 169). Such "disciplinary imperialism" (Defila et al., 2006, p. 42) would mean the end of cross-disciplinarity, because this collaborative work form is already prone to misunderstandings and "self-evidences of one's own discipline are neither known nor necessarily recognized outside" (ibid.). Not only do these differences require a reflexive, non-judgemental and non-hierarchical approach, but the translation and explanation of concepts also require sensitivity towards detecting possible hegemonies of specific terms and theoretical framings (see Weber, 2010 b, p. 101) ${ }^{26}$.

\footnotetext{
${ }^{24}$ Luxembourg has three official languages (Luxembourgish, German and French) that are all taught at school and used in everday life, particularly due to the high proportion of residents with foreign nationality (46\%, http://www.luxembourg.public.lu/fr/actualites/2015/04/08-population/index.html, accessed on 04.05.2016) and cross-border commuters (42\% of employees, see STATEC, 2015: 13). The University of Luxembourg values this multilingualism (its slogan is "Multilingual. Personalised. Connected"), concretely recruits international staff and encourages multilingual work procedures and professional interactions, for example in meetings, teaching and research projects. Both IDENT and IDENT2 were, given their size, multilingual in all work groups. This characteristic is comparable to cross-disciplinary collaboration: it is enriching, but more work intensive, mainly in translation, explicitation and transposition of meanings and concepts. Even though the challenges around multilingual issues may also be an asset for the interdisciplination process (by enhancing translation/convergence processes), the few times when they are explicitly mentionend in our data, they are conceived as 'issues' only. As such mentions are rare, most researchers probably interiorised this Luxembourg-specific multilingualism to such an extent that they use it without commenting - neither as an asset nor as an issue.

${ }^{25}$ It seems to be enhanced among the "per se more dissent- and reflection-oriented humanitites" as opposed to the more pragmatic "application-oriented interdisciplinarity of the techno sciences" (Weber, 2010b, p. 104f.).

${ }^{26}$ Translation policy can indeed be seen as a connecting factor between different academic cultures (see Weber, 2010b, p. 103). At the same time, there is a need for vigilance about which concepts and notions are translated - and which ones are excluded, potentially leading to conceptual dominations (idem, p. 101). It is also key how the translated ones are reconfigured during this integration (idem, p. 94) and how they are appropriated: in a pragmatic-eclectic way, leaving the epistemic foundations and theoretical framings of the respective fields of research untouched, or in a more fundamental way, leading to common, interlaced conceptual and methodological changes (see Weber, 2010a, p. 14).
} 
This suggests that successful cross-disciplinarity does not only depend on the disciplinary competence of its participants, but also on soft skills in terms of interpersonal research negotiation. The science of Team Science (see Hall et al., 2017, p. 338ff.; National Research Council, 2015; Salazar, Lant, Fiore \& Salas, 2012) is a field of study that addresses and models these skills.

\subsection{Researchers' Necessary Skills for Productive Cross-Disciplinarity ${ }^{27}$}

Project participants were asked to give qualitative responses about the kind of skills researchers should have for successful cross-disciplinary collaboration.

Surprisingly, none of the usual concerns from interdisciplinarity literature were expressed. There was no mention of cross-disciplinary collaboration being an extra burden (see Sukopp, 2010, p. 16; see Wiesmann et al., 2008, p. 438; Defila et al., 2006, p. 41; see Blättel-Mink et al., 2003, p. 32; see Frodeman et al., 2017, p. 4), particularly in terms of time and resources ${ }^{28}$ due to the recursivity of this form of work. There was also no mention that this more long-term collaboration could constitute a career risk in the sense that on the one hand it has the potential to be innovative, but on the other that interdisciplinary researchers risk being marginalised as outsiders (see Wahrig \& Zuber, 2010, p. 228f.). This is probably because the team members involved in IDENT/IDENT2 only used part of their allotted research workload for it and continued to conduct other predominantly disciplinary research. The conventional criticism that cross-disciplinary collaboration allows a "reputation-maximising strategy [where] one can have a reasonably honoured reputation as a kind of Renaissance character - and manage, in the process, to avoid detailed scrutiny from either side" (Brennan, 2010, p. 388) is also not mentioned here.

Instead, the empirical suggestions all communicate a pragmatic goodwill that stems from personal, participative experience. These confident viewpoints acknowledge the "challenges to personal identity" (Martin \& Pfirman, 2017, p. 590) that the heightened complexity of crossdisciplinarity brings about.

\subsubsection{Openness and reflexive usage of disciplines}

The term that everybody in our survey agrees on is "openness", at times combined with "curiosity", "patience and talent for explaining", "the calmness to embrace something new", "sensitivity and the willingness to understand and respect other viewpoints". On a general level, "a positive approach to collaboration" seems important, "since cross-discliplinary contexts are usually more complex and require more energy/resources". In a cross-disciplinary context decisions "are often made very slowly on the basis of multi-level and decentralized structures and procedures and are accompanied by intensive discussions"29 (Defila et al., 2006, p. 39).

Our team members do not mention from which standpoint this need for openness is demanded, namely that of a research partnership where the members temporarily function as a team and have no employment relationship among each other, but still collaborate "hierarchically [...] and as colleagues" (ibid.). They are expected to achieve communal results, but also compete with each other. The individual case studies, as smallest units of the project, function as individual projects, but are partly dependent on each other. In the sense that participants' profiling stays orientated towards the original discipline, there is tension between work at the level of the crossdisciplinary partnership (which tends towards being interdisciplinary) and work at the level of the individual projects (which tends towards being disciplinary or multidisciplinary). This emphasises

\footnotetext{
${ }^{27}$ This section is based on qualitative data from IDENT2 only.

${ }^{28}$ The absence of the usual concerns on workload regarding interdisciplinary collaboration may also be linked to our project architecture (guided work groups); none of the administrative work that is usually part of a research project had to be undertaken by the researchers but was dealt with by the project coordinators.

${ }^{29}$ It is the task of the project coordinators to frame and time discussions on decision-making in a way that all voices can be heard, while the project's timeline is respected. This is one of the major issues in the recursive loop structure of such projects.
} 
that not all levels of partnership projects require the same degree of cross-disciplinarity.

Besides openness, most commentaries focus on the reflexive use of disciplines. Here the own discipline is topicalised, or the other participating disciplines, or the interaction between them. In the literature, another common criticism of cross-disciplinary collaboration is "the idea that one must necessarily choose between professional depth or breadth" (Buanes \& Jentoft, 2009, p. 451). Our team members do not mention this dichotomy but provide positive recommendations on how to constructively use a plurality of involved disciplines in line with Buanes and Jentoft's conclusion: "Whether interdisciplinarity is inevitably superficial depends on how much effort is invested in acquiring what other disciplines than one's own have to offer" (ibid.).

Concerning one's own discipline, it is suggested that criticism should be endured, but that one should also be able to communicate one's standpoint and remain flexible while doing so.

Participative processes require "carefully structured, sequenced and selected negotiations and interactions" (Wiesmann et al., 2008, p. 437), as well as expectations and power constellations. With respect to other disciplines, our team members demanded that there should be "no prejudices, no hierarchical thinking towards other disciplines" - something that has been termed "field egotisms" (Blättel-Mink et al., 2003, p. 32) - as well as "tolerance to accept that other disciplines search for insights that one regards as less relevant". The fact that in upfront, quantitative questions hierarchies between disciplines are assessed as unproblematic, but appear more frequently in qualitative statements in subordinate clauses shows that the ideal of "elaborating something communal in such a way that the different perspectives are integrated to something new and what is communal applies for all" (Defila et al., 2006, p. 35) is regarded as an ideal, but only partly corresponds to the often conflicting negotiations between disciplines.

In the interaction between their own and other disciplines, respondents regarded "opening up to others and other topics and perspectives" as important, by "putting aside and always critically reflecting one's own preferences and not conferring sole explanatory hegemony on one's own discipline". Only then is it possible to draw enriching conclusions concerning one's own discipline. In short, cross-disciplinarity is a type of research practice where learning processes of the involved researchers are particularly important ${ }^{30}$.

\subsection{Self-Assessed Learning through Other Disciplines ${ }^{31}$}

There is little detailed evidence in the literature about empirical cross-disciplinarity concerning mutual learning processes among the involved researchers (and about their potential influence on participants' disciplinary practices), as most texts focus on recommendations of the professionalisation, systematisation or improvement of this form of collaboration or on its critique (see Blättel-Mink et al., 2003; Darbellay \& Paulsen, 2008; Wiesmann et al., 2008; Castán Broto et al., 2009; Maasen et al., 2006). Frodeman et al. (2017) do mention learning (theories, communities, styles), albeit mainly in the context of academic teaching of interdisciplinary study programmes.

We focus on learning processes among cross-disciplinary practitioners involved in research. In a similar vein, Boix Mansilla (2010, p. 290ff.) stressed the central skill of "learning to synthetize" in interdisciplinary endeavours, while avoiding reductionism and keeping a critical stance. In the 2017 edition of her book chapter, she calls for a pragmatic constructionist epistemology "that

\footnotetext{
${ }^{30}$ Learning processes also take place in disciplinary contexts - acquiring, fine-tuning and transmitting knowlege are indeed cornerstones of any type of research. The specificity of cross-disciplinarity is that these processes need to be made explicit by/to all team members to enrich and adapt the ongoing and collectively discussed recursive reflexivity.

${ }^{31}$ This section is based on data from both projects.

${ }^{32}$ She defines such an epistemology as follows, drawing on Goodman and Elgin (1988): "As constructionist, this epistemological framework posits that the purpose of inquiry (and in this case learning) is not necessarily the certification or acquisition of 'true' knowledge claims, but the advancement of understanding. Inquiry is not the accumulation of propositional knowledge in the search for certifiable truths. Rather, it seeks a broad, deep, and revisable understanding of its subject matter. Taking a pragmatist stance, the proposed epistemology puts a
} 
foregrounds the construction of purpose-driven, disciplinary-grounded, integrative, and necessarily provisional understandings" (Boix Mansilla, 2017, p. 273).

Such a dynamic vision of cross-disciplinary learning corresponds to our self-reflexive process with sensitivity for contingencies, leverages and barriers. Our self-analysis shows that the development of self-assessed learning is of crucial importance and needs to be addressed in critical cross-disciplinary practice. The ideal is that "collaborations and negotiations should be dominated by a mutual learning attitude, not by positions" (Wiesmann et al., 2008, p. 438). The selfevaluation of both our research projects revealed numerous connections to the participants' own disciplines; their questions, perplexities, criticisms and so forth are not so much an indication of beginners' uncertainties than of relational thinking and a continuously increasing "valueconsciousness through reflexive processes" (ibid.).

4.3.1 Learning occurs primarily in teamwork, followed by epistemic interests and concepts, and then methods

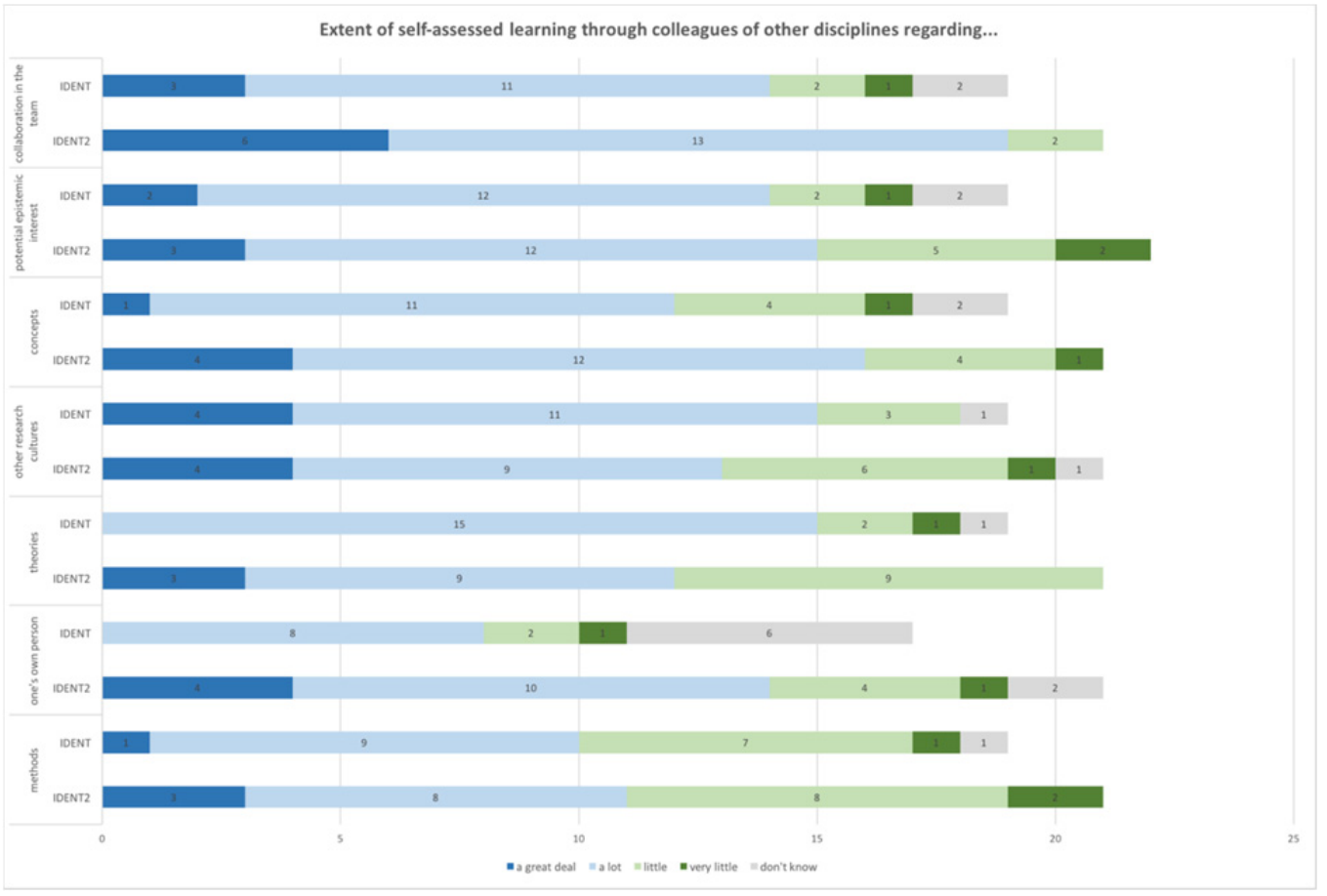

Figure 2: Self-assessed learning through colleagues of other disciplines (in descending order), $\mathrm{N}=$ 17 to 19 for IDENT and 21 to 22 for IDENT2 according to the featured item.

Source: IDENT and IDENT2

In both projects, roughly two thirds of responses refer to positive personal learning processes. If one considers the positive answers (dark blue and light blue on the chart) for both projects, it appears that the self-assessed learning is significantly highest regarding teamwork. This is followed by an intermediary cluster around potential epistemic interests, concepts (scientific notions), other 
scientific cultures as well as, to a lesser extent, theories (scientific models of interpretation). A significantly smaller amount of learning is stated concerning one's own person and the least learning is perceived regarding methods.

\subsubsection{Learning new concepts and theories in teamwork is more straightforward than appropriating new methods or modifying one's fundamental epistemic interests}

In terms of progression from the first to the second project, the perceived personal learning regarding methods remains at a low level ${ }^{33}$. The learning associated with potential new epistemic interests also stays roughly the same, but at a higher level ${ }^{34}$.

The most positive progression from the first to the second project ${ }^{35}$ takes place with learning processes in teamwork ${ }^{36}$. This is followed by positive learning appraisals concerning one's own person ${ }^{37}$. The more reliable and more positive response behaviour for the same item in the second project $^{38}$ suggests that the self-reflective process progressed further. This may be due to the composition of the team in IDENT2 - more post-docs and PhD candidates, for whom it might be easier to perceive themselves as 'learners' than professors. The third positive progression from one project to the next concerns the concepts (scientific notions) ${ }^{39}$.

There are two areas in which the personal learning appraisal decreases from the first to the second project - theories (scientific models of interpretation) ${ }^{40}$ and other research cultures ${ }^{41}$. This may point to a certain familiarity, making learning processes decline, or to a negative evaluation of missed learning opportunities.

All in all, the increased learning assessment in teamwork regarding one's own person and concepts suggests a more in-depth preoccupation with and even an appropriation of such engaging elements during cross-disciplinary interactions. Perceived learning regarding new theories however decreased over time, probably due to a post-structuralist hesitance towards meta-narratives and due to familiarity with the participating disciplines' theorisations. The other learning decrease concerns other research cultures, again probably due to progressive familiarity.

It is noteworthy that learning processes with regard to potential epistemic interests as well as the development of methods did not evolve during the considered time span. This shows that it is generally more straightforward to learn about the intricacies of teamwork, about new concepts and even about new theories than to appropriate new methods or modify one's fundamental epistemic interests during cross-disciplinary transactions.

\subsubsection{Unprecisely qualified learning processes}

In both projects, the qualitative positive comments tend to be formulated in general terms: "great personal enrichment" and "further development/advancement" are frequently mentioned. Personal, not further specified learning processes are often emphasised as stimulating. Other positively connoted learning processes refer to team collaboration but are reproduced in an equally vague way.

In the first project, negative individual opinions about interdisciplinarity were sometimes expressed, but with differing emphasis. We see a defeatist stance when participants write that they

\footnotetext{
${ }^{33} 53 \%$ of answers in the first and $52 \%$ in the second project state a positive learning appraisal.

${ }^{34} 74 \%$ in the first project and $68 \%$ in the second one.

${ }^{35} 63 \%$ in the first project compared to $90 \%$ in the second one.

${ }^{36}$ In the second project, the item of learning something new through collaboration in the team was the only one to be evaluated exclusively in the positive range.

$3747 \%$ of positive assessments.

${ }^{38} 67 \%$.

${ }^{39}$ Which are rated positively from $63 \%$ to $76 \%$.

${ }^{40}$ Drop from $79 \%$ to $57 \%$ of positive learning occurrences.

${ }^{41}$ Decline from $79 \%$ to $62 \%$ of positive learning occurrences.
} 
find it exciting to discover different perspectives on something apparently identical, but think that, given the degree of current specialisations, one would have to work "for years in order to get into a discipline and master it to such an extent that the collaborative work is efficient and productive". In contrast, the expressed "necessity to permanently question one's own terms, concepts and disciplinary approaches" is seen in a more pragmatic, self-reflective light and as something that engenders curiosity.

Team collaboration is confronted pragmatically via specific topics: "To hold together such a group of researchers remains a great challenge that can be met most easily via concrete project work." To diminish the tendency to work "next to each other" - as opposed to "with each other" - it is suggested that there could be a more extensive exchange and confrontation of methods, illustrated with a common case study to show "how each discipline obtains different results with its different perspectives".

\subsubsection{Desideratum concerning knowledge of methods and (more) scientific concepts}

In the second self-evaluation, the question "Regarding which further points would you have liked to have learned more?" was introduced to preempt the lack of specificity in the response behaviour for the first project. The main need for improvement was seen with methodological knowledge ${ }^{42}$, followed by appropriations of scientific concepts of other disciplines.

One team member would have wanted to discuss the "weak points of the various methods, in particular from colleagues' experiences". Such a personalised experience-based approach, balancing the advantages and disadvantages of different methods from research practice, was otherwise never mentioned, although it would clearly represent the added value of crossdisciplinerary collaboration.

The second additional question introduced in the second project, aiming to prompt more specific statements, was "Compared to your usual research activities in your field, what did you do differently in IDENT2?" Methodological aspects were mentioned most frequently in the responses (albeit in vague terms), followed by comments about theories. There are also assessments that reflect that "very little" was done differently, or those who experienced working in IDENT2 as a constraint of their familiar procedures. The increased effort to harmonise and the "coordination with colleagues" are particularly mentioned.

\subsubsection{Stimulating learning processes through teamwork begin with conceptual approaches and are deepened through the development of methods}

In summary, we can say about the first project that qualitatively expressed learning processes about alterities (typified through colleagues of different disciplines) are experienced as stimulating. A first step in this direction - quantitatively and qualitatively detectable - is the curiousity-driven familiarisation with other theoretical concepts. A collaborative (concrete) development of methods would go beyond this first (conceptual) approach in interdisciplinary research practice.

In the second project, the willingness to collaborate appears as frequently as an interest in new concepts and the desideratum of an ongoing development of methods. The latter is most often mentioned as the area in which one would personally have liked to have learned more. Team members who have done more or other things than in their usual research practice - the majority emphasise their personal development concerning particular methodological aspects.

Regarding self-assessed learning processes, it also emerges (quantitatively as well as qualitatively) that team collaboration in the second project was experienced as instructive. More learning processes are mentioned regarding unknown scientific terms than about new scientific models of interpretation. As such models preclude a particular pattern of thinking that is often shaped by the discipline, the willingness to concern oneself with them probably indicates a more

${ }^{42}$ It is possible that this finding can be linked to the project architecture, where the overarching theory and methodology were outsourced to designated work groups and fed back into the content-based work groups. 
profound commitment to interdisciplinary work, compared to the appropriation of more easily accessible terms that can be used as 'component parts' from various perspectives.

The major difference from the first research project is that cross-disciplinary collaboration as such is no longer questioned (in a defeatist or pragmatic way). In the second project, more energy is invested in the reflective optimisation of this collaborative working method.

\subsection{Appraisal of Individual Cross-Disciplinary Research Practice ${ }^{43}$}

\subsubsection{1\% situate themselves between multi- and interdisciplinarity}

The self-evaluation of the first project reflects a certain reticence regarding the assessment of one's own development in the cross-disciplinary process. For this reason, in the second project's selfevaluation a question was introduced regarding one's own working style that only had to be answered quantitatively ${ }^{44}$.

\section{Appraisal of one's own working style in IDENT2}

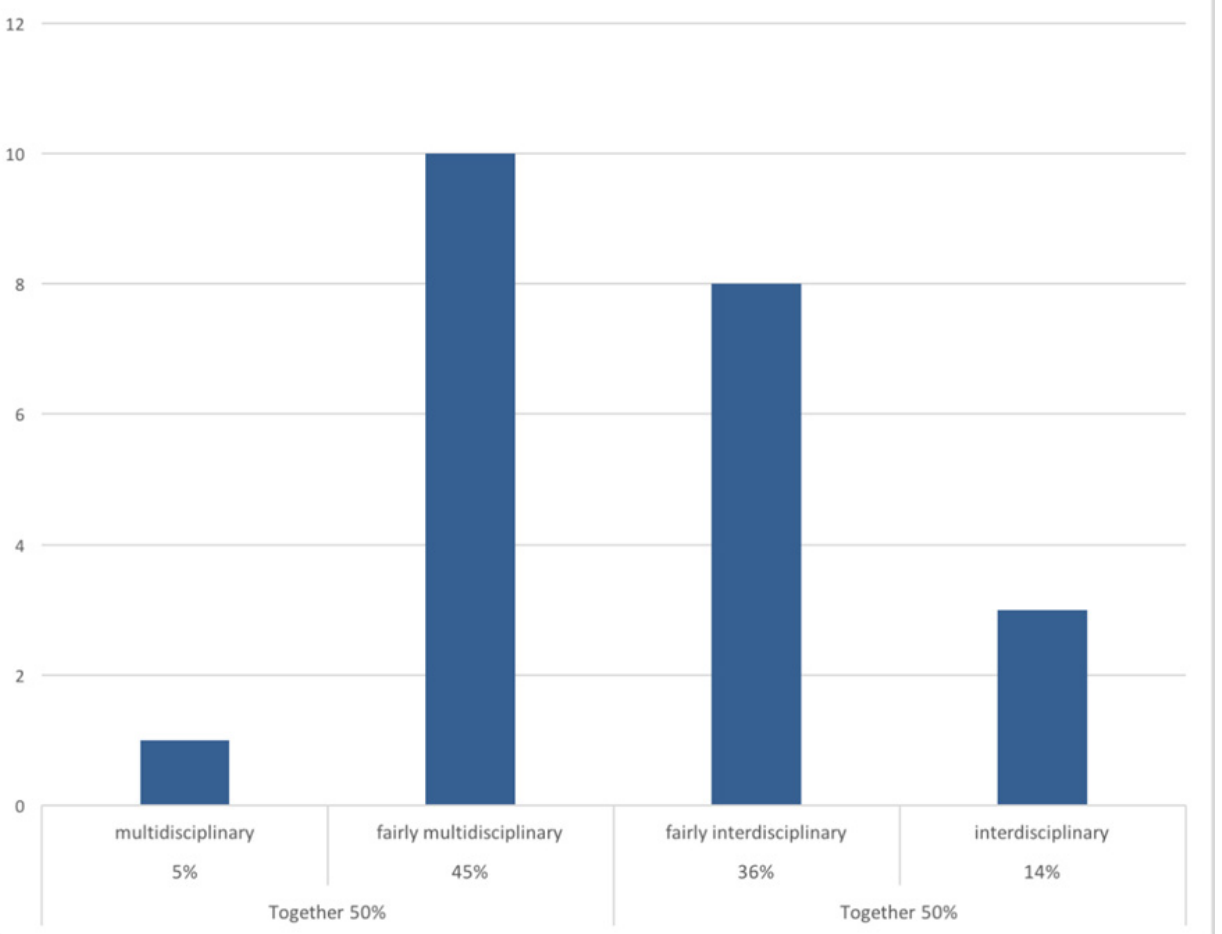

Figure 3: Assessment of one's own working style in IDENT2, N = 22.

Source: IDENT2

Exactly half of the team members viewed their own working style in the second project as predominantly interdisciplinary, while the other half evaluated their working style as predominantly

43 This section is based on data from the second project only.

${ }^{44}$ The response range was on a scale of 4 , where the forced choices moved between multidisciplinary (in the sense of a side-by-side positioning of the disciplines) and interdisciplinary (in the sense of a productive collaboration of the disciplines). 
multidisciplinary. The outcome means that $81 \%$ of all team members place themselves between multi- and interdisciplinarity, with a minority grading themselves as decidedly interdisciplinary; only a minimal percentage view their working style as exclusivly additive.

\subsection{Appraisal of the Work Steps of the Content-Related Work Groups ${ }^{45}$}

In the general evaluation of the content-related work groups in the first project, the hierarchy-free cooperation with colleagues was experienced as enriching, similar to the general evaluation of the project (apart from occasional frustrations regarding work sharing, personnel changes and absenteeism). The added value of the interdisciplinary collaborative research was regarded as having further scope for improvement, particularly to overcome interdisciplinary superficiality.

\subsubsection{Different types of collaboration at different stages}

In the second project, the joint work steps of the thematic work groups were queried in more detail, using five central areas of the chronological project process ${ }^{46}$.

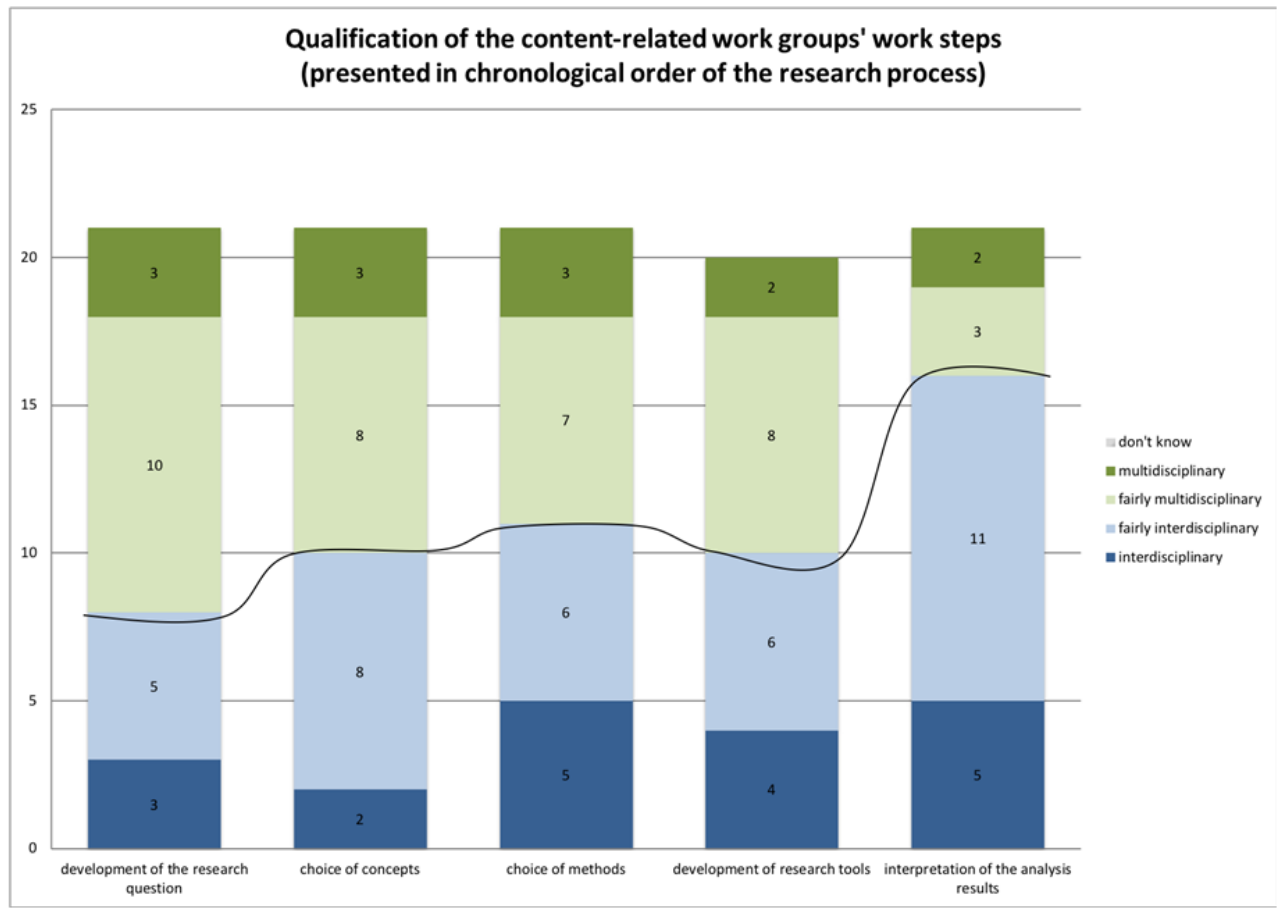

Figure 4: Qualification of the content-related work groups' work steps (presented in chronological order of the research process), $\mathrm{N}=20$ to 21 according to the featured item.

Source: IDENT2

\footnotetext{
${ }^{45}$ This section is based on data from the second project only.

${ }^{46}$ We have defined these five areas empirically, based on our two project architectures. They correspond roughly with the theoretical model Hall et al. (2017, p. 346f.) proposed, identifying four distinct phases: development, conceptualisation, implementation and translation. Incidentally, they also briefly mention the fluidity among those stages: "Although these phases are presented sequentially, the collaborative process is also recognized as recursive, with movement among the phases as the research collaboration unfolds, such that team members may return to prior phases as needed to address unfolding research questions" (idem).
} 
The diagram shows a gradual shift from "fairly multidisciplinary" in the initial research question and the choice of concepts to "fairly interdisciplinary" in the selection of methods, and, decidedly more marked, in the interpretation of the results. Only the development of the research tools is rated equally, as multidisciplinary as well as interdisciplinary.

Research in large cross-disciplinary projects typically takes place at different levels; the individual projects (or case studies) of a cooperation can simultaneously be disciplinary, interdisciplinary or transdisciplinary (see Defila et al., 2006, p. 38), but the common convergence of a subject and a research question is essential, even if it is not sufficient (see Geimer, 2012, p. 5). We solved this by setting up a broad thematic framework and developing common procedures and theoretisations. The individual case studies were allocated to four and three thematic subgroups. The allocation did not occur ex post but corresponded to affinities and decisions at the beginning of the project.

The conceptual and thematic convergences in these thematic work groups were systematically developed bottom-up. This is why it is so important to establish the aimed-for common perspective: it constitutes the frame in which the discipline-specific approaches are contextualised together. Finding a shared research question is the first, basic cross-disciplinary effort, based on the mutual willingness to learn and to question one's own disciplinary ideas.

The choice of methods and the development of investigative tools in both projects were guided by the common epistemic interest. The cross-disciplinarity around methods was constituted differently for everyone: sometimes the methods were familiar to a person and established in their field, and sometimes less familiar ones were used. The common subject was however consensual and formulated in such a way that it had validity in each participating discipline. Only the approaches, perspectives and case studies varied.

As intended in the initial development of a common research question, a successful analysis of results enhances a consensual view of the issue, meaning "developing a perspective that is not identical for all but shared by all" (Defila et al., 2006, p. 36), which corresponds to more than the sum of the individual results. To meet this goal, the collective process of convergence needs to be anchored in the project architecture, reactivated recursively by the project coordinators and enacted by the project members.

\section{Discussion: Situative Interdisciplinarity}

In the self-appraisal of personal research practice and of collective cooperation, it is remarkable that the evaluation of one's own working style is graded at $81 \%$, in the middle of the continuum between a multidisciplinary side-by-side and an interdisciplinary togetherness of disciplines. The qualification of the individual working steps of the thematic work groups is also mostly levelled off in the middle of the continuum, with the development of the research question being regarded as "fairly multidisciplinary" and the interpretation of the results as "fairly interdisciplinary".

One can observe a shift over the course of the project between initial addition right up to a significantly increased convergence when the results are interpreted. It is clear that certain work steps in the research process are more suited for cross-disciplinary convergence than others, namely the method selection and results interpretation. The recursive loop structure of discussions during the project leads to this collective achievement of convergence - the 'interdisciplinary leap' (see diagram) was experienced in the last third of the project and empirically documented in the self-evaluation. The method selection, much earlier, sets the course for gathering data systematically geared towards convergence on which further results are based. It is remarkable that the selected methods are equally suited for interdisciplinary cooperation but were identified in our two self-evaluations as a point that leaves room for improvement. Whether this is an indication of the optimisation potential of our approaches to methods or evidence of a high standard of our team members regarding the treatment of methods, is a matter of interpretation.

The empirical self-analysis of our cross-disciplinary ten-year collaboration suggests in fine that a project that aims at interdisciplinary convergence runs through multidisciplinary project stages: initially, when the research question is developed, but also over the course of the project, with concept selection and development of research tools. As they progress, cross-disciplinary projects 
oscillate between addition and tentative convergence to achieve a significant interdisciplinary leap when the results are interpreted. This is due to building on interdisciplinarily assembled methods throughout the process stages. We have subsumed these linear but not teleological shifts among cross-disciplinary collaboration types that can oscillate flexibly and blend hybridly under the term "situative interdisciplinarity" (Wille, Reckinger et al., 2014, p. 58ff.; 2016, p. 58ff.). At every project stage, their qualification can also undergo a subjectively different interpretation: according to the researchers and the constellation of their contribution in the process, it can be evaluated as multior interdisciplinary.

Figure 5 shows the mobile positioning of the IDENT2 research project on the crossdisciplinary spectrum.

\section{Continuum of Cross-Disciplinary Collaboration}

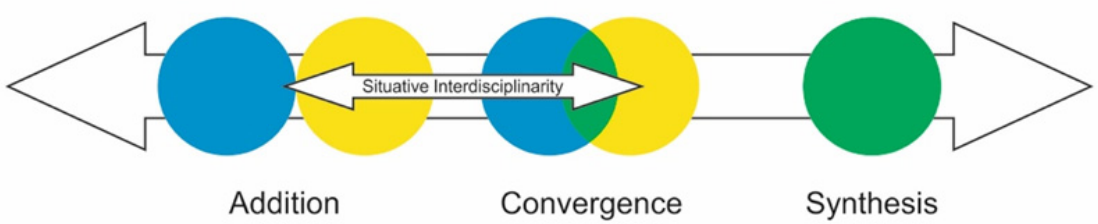

Figure 5: Continuum of cross-disciplinary collaboration with its three basic subforms and flexible positioning of the concept of situative interdisciplinarity, moving in both directions (concept: Christian Wille and Rachel Reckinger; design: Malte Helfer).

Some authors have stressed that in terms of overall research project management, the challenge consists of finding a "balance between periods of intense collaboration with clearly defined joint outputs and periods where deepened disciplinary and multi-disciplinary contributions can be elaborated" ${ }^{7}$ (Wiesmann et al., 2008, p. 438). Instead of a fundamental shift of knowledge production within encompassing cross-disciplinarity culminating in transdisciplinarity (as advocated for instance by Nowotny et al., 2003; Weber, 2010b; Mittelstraß, 2003), in the light of our empirical data a more realistic and pragmatic appraisal is the coexistence of these different types of knowledge - and their hybrid forms (see Mittelstraß, 2005, p. 20) - with the aim not being hierarchisation, but highlighting different potentials (see Maihofer, 2005, p. 202).

We agree with the general argument that "the interdisciplinary researcher is not omniscient, nor a 'jack of all trades but master of none'. He or she is typically a specialist with a substantive research area [...], but also a theoretical and methodological all-rounder or eclectic" (Buanes \& Jentoft, 2009, p. 453). These authors omit the concrete implementation of these considerations. Our empirical grounding allows us to see the constitutive tendency of flexible oscillations between multi- and interdisciplinarity - which also vary subjectively - across the main project stages of cross-disciplinary research. It is the recursive interdisciplination design of research projects such as IDENT/IDENT2, with their typical loops, that foster reflexivity on realistic and varying collaboration outcomes at different stages.

For this situative interdisciplinarity to unfold optimally, it is helpful to consider the level of

\footnotetext{
${ }^{47} \mathrm{Hall}$ et al. even advocate "research that embraces the range of possibilities for independent to collaborative scientific work, from unidisciplinary to transdisciplinary work, at all stages of a research endeavour [as it] will reflect the reality of how research is conducted today and will be of the greatest service to enhancing scientific outcomes, our ultimate goal" (2017, p. 353).
} 
theoretical integration of the participating disciplines (Heckhausen, 1987, p. 132). As institutions, disciplines are definable through research subjects, methods and concepts, but it is not possible to consistently isolate them from one another. This is because subjects and methods overlap, epistimic interests are characterised by historically alterable preferences and theories are variable in scope and depth. Disciplinary borders can also be redrawn (see Löffler, 2010, p. 19).

The most convincing modellisation of disciplinary characteristics that are likely to enhance/inhibit cross-disciplinary collaboration can be found in Aristotle (Metaphysik VI, 1, quoted in Löffler, 2010, p. 161ff.): Aristotle distinguishes the material object and the formal object of a science - the what and the perspective, respectively. Cross-disciplinarity is likely to work most smoothly when "the participating disciplines have the same material object" or "when the respective formal objects are not too dissimilar" or, if these two conditions are not met, "when the laws of relations between the material and formal objects of the participating disciplines are assessable" (idem, p. 162f.) ${ }^{48}$. While the IDENT/IDENT2 projects had common, broadly defined objects subdivided into four and three themes respectively, a collectively negotiated yet plural methodology and an overarching theorisation, they converged material as well as formal objects in a dialectic process. Basically, cross-disciplinarity can succeed optimally when object and method are not both 'alien'49.

The most critical points concern discipline-specific vocabulary, research cultures and teamwork as well as the impact of the chosen approaches to these interwoven aspects of collaboration. These are evaluated in our first project, depending on the degree of optimism the participants exhibit. In the second project, the defeatist attitude is replaced by communicative suggestions to limit misunderstanding around discipline-specific terminology and research cultures. At the same time, a team orientation followed by an open work climate as well as metacommunication on theory, concepts and methods are regarded as necessary for successful cross-disciplinary collaboration (see Salazar et al., 2012, p. 528; see Boix Mansilla, Lamont, \& Sato, $2016^{50}$; see Eigenbrode et al., 2007).

Our team members agree on the necessary openness as well as a reflective approach to interaction between disciplines. This should be characterised by the capacity for dialogue and not be organised hierarchically: showing flexibility towards what is new, being able to communicate one's own position and integrating interesting approaches in one's own scientific modus operandi. The need to explain, translate and clarify discipline-specific terminology is mentioned prominently, clearly showing that these aspects require the most attention in research practice.

We can confirm and/or expand from our empirical experience the following concrete requirements for cross-disciplinary collaboration that Defila et al. (2006, p. 37f.) developed:

- communally defined goals

- communally developed research questions

- a way of communicating that all participants understand, taking into consideration the need to clarify ambiguities and disagreements about terminology and research culture (plus multilingual issues in our case); our experience points to the key importance of translation mechanisms, particularly conceptual ones

- shared research subjects with coherent terminology and identification of relevant features; our project experience showed that this time-intensive work phase is indispensable for the resulting clustering to become meaningful

- bringing together - and negotiating and coordinating - disciplinary concepts in such a way

48 One example of insufficient convergence or even scant addition, the "nice-to-know-interdisciplinarity" (mentioned in Section 2.1: Continuum of Different Forms of Cross-Disciplinary Collaboration), is characterised by not sufficiently similar formal objects or no common material object, without this shortcoming being balanced by interesting contextual principles (see Löffler, 2010: 164).

${ }^{49}$ See Holbrooke (2013) for a discussion of cases where this is not a necessity, namely in the Bataille-Lyotard way of communicating.

50 These authors label the nexus of cross-disciplinary challenges "shared cognitive-emotional-interactional platforms". 
that a shared theoretical approach is available

- agreeing on methods that all members regard as goal-orientated; in our project practice, those methods turned out to be a focal point of which the convergence constituted a particular challenge, but which is indispensable in enabling an interdisciplinary interpretation of the research results

- coordinated contributions; our experience shows that they oscillate, depending on the project stage, flexibly on the cross-disciplinary continuum

- to provide answers to communal research questions, a synthesis is continuously elaborated instead of only being brought together at the end.

From our experience, we add the following point: a central task of the project leaders and coordinators has been accompanying and documenting the exchange in the project group regarding individual understanding, the goals and the realistic realisation of cross-disciplinary collaboration. This should be discussed and reflected in every phase of the project work on the basis of text modules called in at an early stage to attain the widest possible consensus and to develop the jointly supported and practised cross-disciplinary collaboration.

\section{Conclusion}

This paper has set itself the task to show, on the basis of an empirical self-analysis of two consecutive cross-disciplinary research projects over ten years, that and how multi-, inter- or transdisciplinary collaboration is an oscillating process that differs among participants and project stages. If most of the methods are assembled and developed in an interdisciplinary way through communal negotiation processes, a convergent interdisciplinary analysis of research results can be guaranteed through recursive reflexivity loops - despite an initial additive research question and interactions that oscillate during the project process between addition and tentative convergence. We call this process situative interdisciplinarity.

To clarify that there are different types of collaboration that range flexibly and oscillate to both sides on a linear but not teleological continuum, we use the umbrella term cross-disciplinarity. This brings together additive, converging and synthesising work patterns - multidisciplinarity, interdisciplinarity and transdisciplinarity - as the three main forms of cross-disciplinary collaboration, instead of viewing them separately in an ontological manner. One should bear in mind that the most relevant dialectic tension does not occur between multi-, inter- and transdisciplinarity - which in practice show a tendency to coexist or have hybrid forms. Instead, it occurs by referencing disciplinarity and cross-disciplinarity with each other, because they challenge each other, with a resulting, beneficial enhanced reflexivity in both epistemic institutions. This overall view also corresponds to the pragmatic, empirical research practice of broadly conceived joint projects in their structural design, procedures and project stages.

Such an umbrella term also sharpens the awareness of qualities these three collaborative work forms share - they vary particularly regarding the extent of the individual goal the participants envisaged. This makes it possible to understand, appropriate and enrich scientific literature on multi-, inter- and transdisciplinarity as an entity to produce a more unified yet more rigorously differentiated discourse on cross-disciplinarity with all its facets. The common amalgamation of the term 'interdisciplinarity' with both the overarching category of 'more than disciplinary work' (crossdisciplinarity) and a particular collaborative work form (the convergent one, i.e. interdisciplinarity) can therefore be avoided. In this way it becomes clear for which purposes which collaborative work forms make sense (disciplinary or cross-disciplinary) and which type(s) of cross-disciplinarity. This interplay between disciplinary institutions, with the aim to provide input into scientific knowledge (in the case of multi- and interdisciplinarity) and societal problem handling (in the case of transdisciplinarity) is an ongoing negotiation process, which the term "interdisciplination" (Weber, $2010 b$, p. 106), taken from the middle of the cross-disciplinary interaction spectrum, subsumes quite well.

Our empirical analysis follows the call that "researchers should empirically study the effectiveness of trainings [we would like to add: and research projects] designed to enhance the integrative and collaborative capacity of teams during the various phases of collaboration" (Hall et 
al., 2017, p. 353). The recursive design of such research projects and constant reactivation, "problem framing" (Defila \& Di Giulio, 2017, p. 332), timing and mediation by their project coordinators are essential. The collaborative transfer of concepts, theories, methods and research subjects in such endeavours comes at the price of translation, explication and transposition tasks of the various meanings and concepts with regard to discipline-specific vocabulary and disciplinary culture. This is a challenge in cross-disciplinary contexts, carrying the double risk of misunderstanding and conceptual hegemonies, and can only be converged in an open-minded, team-orientated and reflexive work environment ${ }^{51}$. This would ideally be composed of participants with a high level of personal commitment and the willingness to transcend disciplinary boundaries and to embrace other research cultures. It would be a heterogeneous team with little staff turnover, collaborating in a well-thought-through project structure, managed by trained and sensitive research coordinators, aiming to advance socially relevant knowledge.

\section{Acknowledgements}

Rachel Reckinger would like to thank Christian Wille for his assistance in reviewing the manuscript. Christian Schulz, Sonja Kmec and Agnès Prüm have also given valuable inputs on various versions of the manuscript. Many thanks to Matthias Müller, muellertranslations.com, for translating a multilingual text into English and proofreading it. We are also grateful to Ilse Evertse Professional Writing, Editorial \& Translation Services, stellenboschpublishers.nl.

\section{Funding}

This research did not receive any specific grant from funding agencies in the public, commercial or not-for-profit sectors. The two research projects it draws on were funded by the University of Luxembourg's Internal Research Project (IRP) scheme (2007-2010 and 2011-2016).

\section{References}

Balsiger, P. W. (2005). Transdisziplinarität. München: Wilhelm Fink.

Bammer, G. (2013). Disciplining interdisciplinarity. Integration and implementation sciences for researching complex real-world problems. Canberra: The Australian National University.

Barry, A., Born, G., \& Weszkalnys, G. (2008). Logics of interdisciplinarity. Economy and Society, 37(1), $20-49$.

Blättel-Mink, B., Kastenholz, H., Schneider, M., \& Spurk, A. (2003). Nachhaltigkeit und Transdisziplinarität. Ideal und Forschungspraxis. Retrieved from http://elib.uni-stuttgart.de/bitstream/11682/8586/1/ab229.pdf Accessed 3 August 2016.

Boix Mansilla, V. (2010). Learning to synthesize. The development of interdisciplinary understanding. In R. Frodeman, J. Thompson Klein, \& C. Mitcham (Eds.), The Oxford handbook of interdisciplinarity. (pp. 288306). New York: Oxford University Press.

Boix Mansilla, V., Lamont, M., Sato K. (2016). Shared cognitive-emotional-interactional platforms: Markers and conditions for successful interdisciplinary collaborations. Science, Technology and Human Values, 41(4), 571-612.

Boix Mansilla, V. (2017). Interdisciplinary learning. A cognitive-epistemological foundation. In R. Frodeman, J. Thompson Klein, \& R. C. S. Pacheco (Eds.), The Oxford handbook of interdisciplinarity. (2nd ed.). (pp. 261-275). New York: Oxford University Press.

Bortz, J. \& Schuster, C. (2016). Statistik für Human- und Sozialwissenschaftler. Berlin: Springer.

Brennan, G. (2010). PPE: An institutional view. Politics, Philosophy \& Economics 9(4), 379-397.

Castán Broto, V., Gislason, M., \& Ehlers, M-H. (2009). Practising interdisciplinarity in the interplay between disciplines: Experiences of established researchers. Environmental Science \& Policy 12, 922-933.

Buanes, A. \& Jentoft, S. (2009). Building bridges: Institutional perspectives on interdisciplinarity. Futures 41, 446-454.

${ }^{51}$ Bammer (2013, p. 64) argues that "finding appropriate ways to handle unknowns and imperfection" is another pragmatic aspect of cross-disciplinary collaboration. 
Calhoun, C. (2017). Integrating the social siences. Area studies, quantitative methods and problem-oriented research. In R. Frodeman, J. Thompson Klein, \& R. C. S. Pacheco (Eds.), The Oxford handbook of interdisciplinarity. (2nd ed.). (pp. 117-130). New York: Oxford University Press.

Crowley, S., Gonnerman, C., \& O'Rourke, M. (2016). Cross-disciplinary research as a platform for philosophical research. Journal of the American Philosophical Association, 2(2), 344-363.

Darbellay, F. \& Paulsen, T. (eds.) (2008). Le défi de l'inter- et transdisciplinarité. Concepts, méthodes et pratiques innovantes dans l'enseignement et la recherche / Herausforderung Inter- und Transdisziplinarität. Konzepte, Methoden und innovative Umsetzung in Lehre und Forschung. Lausanne: Presses polytechniques et universitaires romandes.

Defila, R., Di Giulio, A., \& Scheuermann, M. (2006). Forschungsverbundmanagement. Handbuch für die Gestaltung inter- und transdisziplinärer Projekte. Zürich: vdf Hochschulverlag AG.

Defila, R. \& Di Giulio, A. (2017). Managing consensus in inter- and transdisciplinary teams. Tasks and expertise. In R. Frodeman, J. Thompson Klein, \& R. C. S. Pacheco (Eds.), The Oxford handbook of interdisciplinarity. (2nd ed.). (pp. 332-337). New York: Oxford University Press.

Després, C. \& Lawrence, R. J. (2004). Introduction. Futures of transdisciplinarity. Futures 36, 397-405.

Douglas, M. (1986). How institutions think. New York: Syracuse University Press.

Eigenbrode, S., O'Rourke, M., Wulfhorst, J. D., Althoff, D., Goldberg, C., Merrill, K., ... \& Bosque-Pérez, N. (2007). Employing philosophical dialogue in collaborative science. BioScience, 57(1), 55-64.

Frodeman, R., Thompson Klein, J., \& Mitcham, C. (Eds.). (2010). The Oxford handbook of interdisciplinarity. New York: Oxford University Press.

Frodeman, R., Thompson Klein, J., \& Pacheco, R. C. S. (Eds.). (2017). The Oxford handbook of interdisciplinarity. (2nd ed.). New York: Oxford University Press.

Geimer, P. (2012, 15 August). Wir schenken euch die Neuronen gerne. Am lautesten rufen nicht Wissenshaftler, sondern Drittmittelgeber und Politiker nach grenzüberschreitender Forschung. Doch wer sagt eigentlich, dass die beste aller Welten interdisziplinär ist? Frankfurter Allgemeine Zeitung, p. 5.

Gehring, P. (2013). Technik in der Interdisziplinaritätsfalle. Anmerkungen aus Sicht der Philosophie. Journal of Technical Education 1, 132-146.

Hacking, I. (2010). Verteidigung der Disziplin. In M. Jungert, E. Romfeld, T. Sukopp, \& U. Voigt (Eds.), Interdisziplinarität. Theorie, Praxis, Probleme. (pp 193-206). Darmstadt: Wissenschaftliche Buchgesellschaft.

Hall, K. L., Stipelman, B. A., Vogel, A. L., \& Stokols, D. (2017). Understanding cross-disciplinary team-based research. Concepts and conceptual models from the science of team science. In R. Frodeman, J. Thompson Klein, \& R. C. S. Pacheco (Eds.), The Oxford Handbook of Interdisciplinarity. (2nd ed.). (pp. 338-356). New York: Oxford University Press.

Hark, S. (2005). Inter/Disziplinarität. Gender studies revisited. In H. Kahlert, B. Thiessen, \& I. Weller (Eds.), Quer denken - Strukturen verändern. Gender studies zwischen Disziplinen. (pp. 61-89). Wiesbaden: Verlag für Sozialwissenschaften.

Heckhausen, H. (1987). Interdisziplinäre Forschung zwischen Intra-, Multi- und Chimären-Disziplinarität. In J. Kocka (Ed.), Interdisziplinarität: Praxis - Herausforderung - Ideologie. (pp. 129-145). Berlin: Suhrkamp.

Holbrooke, B. (2013). What is interdisciplinary communication? Reflections on the very idea of disciplinary integration. Synthese. An International Journal for Epistemology, Methodology and Philosophy of Science, 190(11), 1865-1879.

Huutoniemi, K. \& Rafols, I. (2017). Interdisciplinary research evaluation. In R. Frodeman, J. Thompson Klein, \& R. C. S. Pacheco (Eds.), The Oxford handbook of interdisciplinarity. (2nd ed.). (pp. 498-512). New York: Oxford University Press.

IPSE (ed.) (2011). Doing identity in Luxembourg. Subjective appropriations - Institutional attributions - Sociocultural milieus. Bielefeld: Transcript Verlag.

Jacobs, J. A. (2017). The need for disciplines in the modern research university. In R. Frodeman, J. Thompson Klein, \& R. C. S. Pacheco (Eds.), The Oxford handbook of interdisciplinarity. (2nd ed.). (pp. 35-39). New York: Oxford University Press.

Jungert, M. (2010). Was zwischen wem und warum eigentlich? Grundsätzliche Fragen der Interdisziplinarität. In M. Jungert, E. Romfeld, T. Sukopp, \& U. Voigt (Eds.), Interdisziplinarität. Theorie, Praxis, Probleme. (pp. 1-11). Darmstadt: Wissenschaftliche Buchgesellschaft.

Lawrence, R. J. (2010). Deciphering interdisciplinary and transdisciplinary contributions. Transdisciplinary Journal of Engineering \& Science, 1(1), 125-130.

Löffler, W. (2010). Vom Schlechten des Guten: Gibt es schlechte Interdisziplinarität? In M. Jungert, E. Romfeld, T. Sukopp, \& U. Voigt (Eds.), Interdisziplinarität. Theorie, Praxis, Probleme. (pp. 157-172). Darmstadt: Wissenschaftliche Buchgesellschaft.

Maasen, S., Lengwiler, M., \& Guggenheim, M. (2006). Practices of transdisciplinary research: Close(r) encounters of science and society. Science and Public Policy 33(6), 394-398. 
Maihofer, A. (2005). Inter-, Trans- und Postdisziplinarität. Ein Plädoyer wider die Ernüchterung. In H. Kahlert, B. Thiessen, \& I. Weller (Eds.), Quer denken - Strukturen verändern. Gender Studies zwischen Disziplinen. (pp. 185-202). Wiesbaden: Verlag für Sozialwissenschaften.

Mäki, U., Walsh, A., \& Fernandez Pinto, M. (2018). Scientific imperialism. Exploring the boundaries of interdisciplinarity. New York: Routledge.

Martin, P. J. R. \& Pfirman, S. (2017). Facilitating interdisciplinary scholars. In R. Frodeman, J. Thompson Klein, \& R. C. S. Pacheco (Eds.), The Oxford handbook of interdisciplinarity. (2nd ed.). (pp. 586-600). New York: Oxford University Press.

Mayring, P. (2007). Qualitative Inhaltsanalyse. Grundlagen und Techniken. Weinheim: Beltz.

Mittelstraß, J. (2003). Transdisziplinarität. - wissenschaftliche Zukunft und institutionelle Wirklichkeit. Konstanz: Universitätsverlag Konstanz.

Mittelstraß, J. (2005). Methodische Transdisziplinarität. Technikfolgeabschätzung - Theorie und Praxis 14(2), 18-23.

National Research Council. (2015). Enhancing the effectiveness of team science. Washington, DC: National Academies Press.

Nowotny, H., Scott, P., \& Gibbons, M. (2003). Introduction. 'Mode 2' revisited: The new production of knowledge. Minerva 41, 179-194.

O'Rourke, M. (2017). Comparing methods for cross-disciplinary research. In R. Frodeman, J. Thompson Klein, \& R. C. S. Pacheco (Eds.), The Oxford handbook of interdisciplinarity. (2nd ed.). (pp. 276-290). New York: Oxford University Press.

Pohl, C. \& Hirsch-Hadorn, G. (2008). Methodological challenges of transdisciplinary research. Natures Sciences Sociétés 16(2), 111-121.

Pohl, C., Truffer, B., \& Hirsch-Hadorn, G. (2017). Addressing wicked problems through transdisciplinary research. In R. Frodeman, J. Thompson Klein, \& R. C. S. Pacheco (Eds.), The Oxford handbook of interdisciplinarity. (2nd ed.). (pp. 319-231). New York: Oxford University Press.

Reckinger, R. (2011): Auswertung der Selbstevaluation des IDENT-Projekts (2007-2010). IDENT2-Working Papers 0, Luxembourg (71 p.), https://wwwen.uni.lu/research/flshase/home/publications.

Reckinger, R. (2015): Auswertung der Selbstevaluation des IDENT2-Projekts (2011-2014). IDENT2-Working Papers 7, Luxembourg (67 p.), https://wwwen.uni.lu/research/flshase/home/publications.

Salazar, M. R., Lant, T. K., Fiore, S. M., \& Salas, E. (2012). Facilitating innovation in diverse science teams through integrative capacity. Small Group Research, 43(5), 527-558.

STATEC (2015). Le Luxembourg en chiffres. Institut national de la statistique et des études économiques, Luxembourg.

Stokols, D. (2006). Toward a science of transdisciplinary action research. American Journal of Community Psychology, 38(1-2), 63-77.

Sukopp, T. (2010). Interdisziplinarität und Transdisziplinairtät. Definitionen und Konzepte. In M. Jungert, E. Romfeld, T. Sukopp, \& U. Voigt (Eds.), Interdisziplinarität. Theorie, Praxis, Probleme. (pp. 13-29). Darmstadt: Wissenschaftliche Buchgesellschaft.

Thompson Klein, J. (1990). Interdisciplinarity. History, theory and practice. Detroit: Wayne State University Press.

Thompson Klein, J. (2015). Reprint of "Discourses of transdisciplinarity. Looking back to the future". Futures, 65, p. 10-16.

Thompson Klein, J. (2017). "Typologies of interdisciplinarity. The boundary work of definition”. In R. Frodeman, J. Thompson Klein, \& R. C. S. Pacheco (Eds.), The Oxford handbook of interdisciplinarity. (2nd ed.). (pp. 21-34). New York: Oxford University Press.

Thompson Klein, J. \& Frodeman, R. (2017). Interdisciplining humanities. A historical overview. In R. Frodeman, J. Thompson Klein, \& R. C. S. Pacheco (Eds.), The Oxford handbook of interdisciplinarity. (2nd ed.). (pp. 144-156). New York: Oxford University Press.

Wahrig, B. \& Zuber, S. (2010). InterViduum. Perspektiven auf die/den interdisziplinierte/n Wissenschaftler/in. In J. Weber (Ed.), Interdisziplinierung? Zum Wissenstransfer zwischen den Geistes-, Sozial- und Technowissenschaften. (pp. 215-237). Bielefeld: Transcript Verlag.

Weber, J. (2010a). Interdisziplinarität und Interdisziplinierung. Eine Einleitung. In J. Weber (Ed.), Interdisziplinierung? Zum Wissenstransfer zwischen den Geistes-, Sozial- und Technowissenschaften. (pp. 11-27). Bielefeld: Transcript Verlag.

Weber, J. (2010b). Interdisziplinierung? Zur Übersetzungspolitik einer neuen Technowissenschaftskultur. In J. Weber (Ed.), Interdisziplinierung? Zum Wissenstransfer zwischen den Geistes-, Sozial- und Technowissenschaften. (pp. 83-112). Bielefeld: Transcript Verlag.

Wiesmann, U., Biber-Klemm, S., Grossenbacher-Mansuy, W., Hirsch-Hadorn, G., Hoffmann-Riem, H., Joye, D., Pohl, C., \& Zemp, E. (2008). Enhancing transdisciplinary research: A synthesis in fifteen propositions. In G. Hirsch-Hadorn, H. Hoffmann-Riem, S. Biber-Klemm, W. Grossenbacher-Mansuy, D. Joye, C. Pohl, U. Wiesmann, \& E. Zemp (Eds.), Handbook of transdisciplinary research. (pp. 433-441). Berlin: Springer. 
Wille, C., Reckinger, R., Kmec, S., \& Hesse, M. (Eds.) (2016). Spaces and identities in border regions. Politics Media - Subjects. Bielefeld: Transcript Verlag. 